\title{
llustrações Científicas e a Classificação do Mundo Natural no Século XVIII: Considerações para o Ensino de Ciências
}

\author{
Scientific Illustrations and the Classification of the Natural World in the \\ Eighteenth Century: Considerations for Science Teaching
}

(D) Fernanda Cavalcanti Vitor, André Ferrer Pinto Martins

Palavras-chave

Ilustrações

Científicas;

História Natural;

Século XVIII;

Ensino de Ciências;

História, Filosofia

e Sociologia da

Ciência.
Resumo O objetivo geral desse trabalho éapresentar uma investigação sobre a importância e o significado da utilização das ilustrações científicas no processo de classificação do mundo natural no século XVIII, apontando as contribuições do entendimento desse processo histórico e dos seus sentidos para o ensino de ciências da natureza. Para tanto, realizamos um estudo historiográfico acerca das ilustrações científicas, explorando o seu contexto histórico e sociocultural de produção, com foco na História Natural iluminista, trazendo uma descrição dos elementos característicos desse tipo de imagem da época sinalizada. Enxergamos uma lacuna, principalmente no Brasil, acerca desse tipo investigação, que considera as ilustrações científicas como fontes históricas de pesquisa e que propõe uma articulação com o ensino de ciências, na interface com a história, a filosofia e a sociologia da ciência. Defendemos que uma ilustração científica se configura em um tipo específico de representação visual da natureza, que foi essencial para o conhecimento taxonômico de plantas e animais no século XVIII, como também reconhecemos que a partir do estudo dessas ilustrações e do seu contexto de produção é possível refletir sobre aspectos relevantes da natureza da ciência. Em suma, pretendemos trazer as ilustrações científicas históricas para o ensino de ciências e mostrar que essas imagens têm suas potencialidades e não merecem ser tratadas apenas como recursos figurativos, quando levadas à sala de aula. 
Keywords Abstract The general aim of this paper is to present an investigation Scientific into the importance and meaning of scientific illustrations in the Illustrations; process of classification of the natural world in the eighteenth century, Natural History; pointing out the contributions of the understanding of this historical Eighteenth Century; process and its meanings for natural science teaching. Therefore, we Science Teaching; performed a historiographic investigation of scientific illustrations, History, Philosophy exploring historical and sociocultural contexts of production, focusing and Sociology of on enlightenment Natural History, in a way to describe characteristic

Science. elements of this type of image of the indicated epoch. Especially in Brazil, there is a lack of investigations of this kind, i.e., studies that consider scientific illustrations as historical sources of research and that propose an articulation between this type of image and science teaching, in an interface between history, philosophy, and sociology of science. We argue that scientific illustrations act as a specific type of visual representation of nature, which was essential to taxonomic knowledge of plants and animals in the eighteenth century, as we also recognize that it is possible to reflect about relevant aspects of the nature of science from the study of these scientific illustrations and their contexts of production. Overall, we intend to bring scientific illustrations into science teaching and show that these visual representations have potentialities, and must not be treated merely as figurative resources when brought into the classroom.

\section{Introdução}

Nas últimas décadas, historiadores têm sinalizado que as imagens passaram de meras representações para fontes de investigação, suscetíveis de serem interrogadas, lidas e interpretadas da mesma forma que um texto escrito. As ilustrações suportam um enredo de ideias, práticas e interações sociais que fazem parte do trabalho científico, aliás, há uma possibilidade de compreender e fazer uma releitura de regras ou convenções a partir do uso de imagens em uma determinada cultura. Nessa direção, as representações visuais, que também correspondem a um registro de naturalistas, podem nos fornecer uma história riquíssima de informações envolvendo a ciência e o seu contexto histórico e sociocultural de produção e utilização (Antunes et al., 2015; Burke, 2008, 2017; Costa, 2006; Ford, 1993; Gombrich, 2012, 2015, Pimentel, 2010).

As representações visuais compreendem uma área de domínio das imagens que foram desenvolvidas por seres humanos em suas respectivas sociedades. São imagens artificialmente produzidas, mediadas por habilidades, instrumentos e técnicas necessários à sua elaboração. Podem ser inscritas de forma manual sobre uma superfície, bem como capturadas através de recursos ópticos de ampliação, como telescópios e microscópios. Correspondem a desenhos, pinturas, gravuras, diagramas, mapas etc. Aguçar e aumentar a nossa percepção e regenerar a nossa sensibilidade visual são algumas dentre as várias 
finalidades das representações visuais. Além disso, esse tipo de imagem apresenta múltiplas camadas, como camadas subjetivas, sociais, estéticas, antropológicas, tecnológicas, científicas (Santaella, 2012), que sofrem modificações de acordo com o tempo e com as questões sociocientíficas de uma determinada época.

Segundo Aumont (2012), a representação visual é definida como uma imagem que tem a intenção de mostrar a realidade e, ao mesmo tempo, proferir um discurso sobre ela. Contudo, o valor representativo da imagem vai ao encontro das convenções do seu período histórico e está inclinado às subjetividades e às concepções artísticas de quem a elaborou (Aumont, 2012). Nesse sentido, uma representação visual não carrega, apenas, uma intenção de buscar semelhança com o objeto retratado, mas, também, reflete aspectos do seu contexto de produção e, assim, revela os interesses dos diversos personagens envolvidos na sua confecção.

Santaella (2012) considera senso comum a ideia de que uma imagem se assemelha a seus objetos de referência. Para ela, essa discussão de naturalidade da imagem representativa compreende uma concepção de certos autores que se recusam à prática de leitura de imagem, que alegam que não há mais nada para dizer de uma imagem que apresenta semelhança com aquilo que representa, pois a percepção e o reconhecimento do conteúdo desse tipo de imagem são rápidos e simultâneos. Mas, a autora enfatiza que, apesar de existirem esquemas mentais universais comuns a todos os seres humanos e que norteiam a percepção visual, "o simples reconhecimento não nos fornece as chaves para a interpretação dessas imagens" (Santaella, 2012, p. 23). Portanto, seria um erro crer que as imagens representavam de fato o objeto "exatamente como ele foi visto". O real se apresentaria, apenas, aos olhos daqueles a quem foram ensinadas as convenções (Daston \& Galison, 2010).

De forma semelhante, estudantes, principalmente da Educação Básica, têm uma concepção de que proposições científicas - o que inclui as ilustrações científicas representam o mundo "tal como ele, de fato, é". Essa noção se aproxima, por exemplo, do que Gil Perez et al. (2001, p. 127) chamam de uma "visão deformada do trabalho científico". Dito isto, essa ideia de que uma ilustração científica representa o objeto natural de forma fidedigna, no sentido de um "realismo ingênuo", compreende, portanto, um tema bastante relevante para o ensino de ciências e que poderia ser abordado, também, através das ilustrações científicas históricas.

Já para Foss (1971), a semelhança como critério de representação é um mito. O que se entende é que "vemos o mundo como nossas convenções existentes (categorias, regras de projeção) nos permitem vê-lo. Crer é ver. Nosso mundo é esse mundo" (Foss, 1971). As convenções vigentes são responsáveis por monitorar o sentido do "mundo" ou "realidade", porém, é preciso superar essa ideia de que há algo "lá fora" a ser representado simbolicamente (pictoricamente ou cientificamente) de modo singular. "Há mais para ser visto do que aquilo que chega ao globo ocular" (Foss, 1971). 
Em síntese, precisamos ter atenção para como estamos lidando ou interpretando as representações visuais e entender que nenhuma imagem se limita à "pura" verossimilhança do objeto observado. Ao contrário, cada representação visual equivale a uma expressão de símbolos característicos da sociedade vigente e com o propósito de corresponder a certas expectativas, bem como compreende o resultado de um esforço cognitivo.

Nesse sentido, a noção de representação como algo que se limita a imitar algo específico "lá fora" precisa ser ultrapassada, principalmente, por nós, receptores dessas imagens. Cada representação compreende um estilo ou um sistema simbólico particular e está carregada de convenções e concepções que mudam com o passar do tempo. Assim, cada representação pode ser lida, interpretada e deve ser analisada criticamente, contextualmente (Foss, 1971).

Contudo, enxergamos que existe uma lacuna, principalmente no Brasil, acerca desse tipo investigação, que valoriza as representações visuais da natureza como fontes históricas de pesquisa, especialmente no campo do ensino de ciências. Além disso, ao estudarmos a literatura da área, percebemos que as ilustrações científicas ainda são pouco exploradas, sabe-se pouco sobre elas e sobre suas potencialidades, bem como são escassos os estudos que propõem uma articulação entre as ilustrações científicas e o ensino de ciências, na interface com a história, a filosofia e a sociologia da ciência (HFSC), ou seja, através de uma abordagem da moderna historiografia da ciência (Vitor \& Martins, 2020).

Considerando o exposto, o objetivo principal desse trabalho é apresentar uma investigação sobre a importância e o significado da utilização das ilustrações científicas no processo de classificação do mundo natural no século XVIII, apontando as contribuições do entendimento desse processo histórico e dos seus sentidos para o ensino de ciências da natureza. Buscamos explorar as ilustrações científicas no processo de "descoberta", de organização e de catalogação da natureza, especialmente no "século das luzes", isto é, entender o seu passado, explicá-lo, descrevê-lo, contribuindo para uma compreensão de como se dá a interação entre a atividade científica e a sociedade mais ampla e as relações do conhecimento científico com diversos setores da cultura (Abrantes, 2002).

Em conjunto, a nossa proposta é trazer uma contribuição relacionada ao uso das ilustrações científicas como fonte histórica no ensino de ciências, particularmente à área de HFSC no Ensino. Assim, procuramos desenvolver esse estudo histórico aprofundado dentro de determinado recorte, mas que possibilita traçar consequências mais amplas para a educação científica.

Bleichmar (2012) relata que, no século XVIII, os naturalistas produziram muito mais imagens do que descrições textuais, e os enormes esforços realizados por esses estudiosos, como empregar, treinar e supervisionar os artistas, bem como as frequentes discussões sobre História Natural e as ações de patrocinadores, resultaram em um vasto arquivo visual do período em destaque. Tal feito, portanto, sugere que as ilustrações científicas tiveram uma importância central tanto para a exploração da natureza, especialmente do novo mundo, quanto para tornar visível a expansão e o domínio dos impérios. 
A História Natural, nessa era iluminista, toma a classificação dos seres vivos como estudo principal, particularmente um sistema de classificação com base em certas partes das plantas. Nessa época, novas propostas de categorização do mundo natural são definidas e têm como referência o naturalista sueco Carl Linnaeus (1707-1778). O botânico lançou enfoques novos a ideias antigas e desenvolveu um sistema de classificação tomando como base as estruturas sexuais das plantas (Lindroth, 2007; Santos, 2006). A História Natural iluminista esteve situada entre uma cultura aristocrática do saber e uma cultura que legitimava o conhecimento sistematizado como forma de proporcionar maior bem-estar material para a sociedade (Kury, 2015).

Assim, adotamos o recorte histórico da História Natural na era iluminista, com foco no sistema de classificação de seres vivos, como pano de fundo para evidenciar, também, os elementos característicos das ilustrações científicas, detalhando o seu papel nesses estudos da natureza da época sinalizada, com vistas a problematizar a ciência e suas práticas e, consequentemente, apontar as implicações desse estudo para o ensino de ciências na interface com a HFSC e a natureza da ciência (NdC).

Partimos da premissa que uma ilustração científica ${ }^{1}$ se configura em um tipo específico de representação visual da natureza que foi essencial para identificar estruturas e características distintivas dos espécimes e divulgar o conhecimento taxonômico de plantas e animais no século XVIII. Enxergamos, ainda, que, a partir do seu contexto histórico e sociocultural de produção, torna-se possível refletir sobre aspectos relevantes de NdC.

Os referenciais da História da Ciência, na sua perspectiva moderna, que valoriza o contexto sociocultural de um determinado tema, serviram de aporte teórico e metodológico para o desenvolvimento dessa pesquisa. Nesse caminho, utilizamos as investigações de historiadores, de historiadores da ciência e de historiadores da arte.

Trata-se, portanto, de um estudo de natureza bibliográfica, de caráter interdisciplinar e embasado na literatura da moderna historiografia da ciência, especialmente na vertente da História Cultural da Ciência (Jardim \& Guerra, 2017; Moura \& Guerra, 2016; Pimentel, 2010; Silva, 2016). De acordo com esses autores, a História Cultural da Ciência, através da sua rica descrição, valoriza a história das ações individuais ou coletivas relacionadas, por exemplo, com os instrumentos, com os próprios cientistas e com os espaços, como laboratórios, academias, entre outros tipos de instituições. Converge com as visões alternativas à História da Ciência mais tradicional, marcadas pelos estudos sociológicos do conhecimento científico, bem como tem referência na antropologia, nos estudos culturais e na história cultural em si.

\section{História Natural: do renascimento ao iluminismo}

Considera-se que a História Natural ressurgiu na Europa Ocidental, especialmente, entre os séculos XV e XVII. A princípio, a natureza era um assunto para alegorias, comentários ou para a medicina, ou seja, não havia muito interesse na descrição abrangente e organizada do mundo natural. Além disso, cada segmento da sociedade

1 Em nosso estudo, essa expressão se refere a uma imagem fixa que busca retratar a natureza por meio, por exemplo, de desenhos de plantas, de animais, da anatomia humana, dentre outros. 
- as escolas da catedral, as universidades e os tribunais - desenvolveu uma forma particular de discurso adequada ao seu contexto imediato. Por outro lado, percebe-se uma mudança de perspectiva nos estudos de plantas e de animais a partir desse período renascentista, e isso se deve às novas circunstâncias sociais do naturalismo, da reverência pelo aprendizado antigo e pelas viagens de exploração e descoberta (Findlen, 2000).

Nessa direção, a História Natural emergiu como uma disciplina intimamente conectada com vários movimentos e desenvolvimentos da cultura do renascimento, como o movimento cultural do humanismo, o intenso interesse contemporâneo pelo empirismo, o colecionismo, a cultura de curiosidades e a emergência de novas formas de organização científica. Nesse momento, humanistas com interesse em História Natural já podiam ser encontrados nas principais cortes da Renascença e os patrícios passaram a enxergar o aprendizado como uma atividade de lazer apropriada, bem como os governantes começaram a financiar as atividades de estudiosos que foram surgindo, provocando um intenso interesse pela descrição precisa do mundo natural. Em suma, a História Natural passou a ser vista por muitos representantes da sociedade da época como um assunto nobre, agradável e útil, digno em todos os aspectos de seu patrocínio (Findlen, 2000; Ogilvie, 2006).

Hankins (2010) também sinaliza algumas outras razões para esse novo entusiasmo pela História Natural, inclusive numa época em que a filosofia mecânica predominava nas investigações. Um desses motivos era religioso. Por exemplo, alguns filósofos mecanicistas ${ }^{2}$ reconheciam um Deus criador, mas lhe negavam qualquer papel nas operações cotidianas do universo. Portanto, Deus podia ser conhecido na natureza apenas pela extraordinária complexidade e harmonia de sua criação, e a História Natural descrevia essa complexidade em grande detalhe. Uma segunda razão para o sucesso da História Natural foi o desejo de se livrar dos "princípios" e "almas" animistas que caracterizaram a ciência renascentista. A História Natural descreveu e classificou todos os três reinos da natureza - animal, vegetal e mineral - e, como uma ciência de formas e categorias, não precisava se preocupar com as causas da vida. Uma terceira razão para esse ressurgimento da História Natural foi a ênfase crescente, especialmente na Inglaterra, nas ciências empíricas. Para alguns filósofos naturais, o mundo deveria ser conhecido a partir de cuidadosa observação e estudo de fenômenos naturais, e não a partir do raciocínio dedutivo sobre princípios abstratos.

Findlen (2000) destaca que, nesse período renascentista, a História Natural era considerada tátil e visual, e não exigia nenhum conhecimento específico para ser apreciada, diferentemente dos componentes tradicionais da filosofia natural, ou seja, qualquer pessoa, de diferentes áreas de conhecimento, poderia desenvolver pesquisa em História natural ou participar desse campo de conhecimento, incluídos até aqueles que não teriam nenhuma formação. Os poucos naturalistas profissionais eram acompanhados

2 Na era moderna, buscava-se construir uma teoria que explicasse a totalidade dos fenômenos da natureza, e a concepção mecanicista, que associava o universo a uma máquina, foi uma das suas principais bases. Não havia uma visão uniforme na filosofia mecanicista, mas, de modo geral, tentava-se compreender o funcionamento da natureza por meio de engrenagens, movimentos repetitivos e pela matemática (Braga et al., 2011). 
não apenas por assistentes que coletavam e registravam o que observavam, mas também por patrícios ricos que não podiam imaginar maior prazer do que uma excursão ao campo. Além disso, a capacidade dos naturalistas de organizar objetos de maneiras agradáveis em seus gabinetes e a habilidade com que os artistas capturavam os contornos da natureza na tela serviram para aumentar o prazer estético de ver a natureza.

Nesse caminho, muitos artistas da corte fizeram das ilustrações naturalistas sua nova ocupação. Houve uma incorporação de habilidades artísticas e literárias em História Natural, e os subsídios fornecidos pelos tribunais mais conhecidos, que cultivavam a aprendizagem da arte, foram cruciais nesse processo de revitalização dos estudos da natureza. Inclusive, sob patrocínio imperial, principalmente, muitas obras clássicas foram traduzidas para vários idiomas, como também foram produzidas muitas imagens para acompanhar os textos (Findlen, 2000). Vale ressaltar que esses livros impressos com ilustrações eram relativamente caros, produções luxuosas que eram, geralmente, criadas como cópias de dedicação aos clientes (Kusukawa, 2000, 2011).

No que se refere às atividades profissionais dos naturalistas, muitos deles também trabalhavam em ambientes urbanos como professores universitários, curadores dos jardins botânicos, médicos, boticários etc., fomentando, inclusive, um outro tipo de patrocínio, o patrocínio urbano. Dessa forma, a História Natural se popularizou mais rapidamente, pois se adaptou bem à cultura de mercado da cidade, onde os produtos eram trocados e vendidos. Em várias cidades, clérigos, advogados, médicos e outros notáveis cultivaram jardins e museus e participaram do ciclo interminável de visitas, trocas e demonstrações que definiram o mundo da coleta. As coleções começaram a se tornar mais difusas à medida que a História Natural se integrava às atividades de lazer da elite urbana (Findlen, 2000).

Outro ponto que merece destaque, também apontado por Findlen (2000), é como os naturalistas individuais captavam recursos, pois a grande parte, incluindo os colecionadores mais bem sucedidos, dependia de presentes para completar suas enciclopédias da natureza, que geralmente vinham de famosos cardeais, bispos, arcebispos, duques, barões, condes, médicos e estudiosos que haviam contribuído com os objetos que eles classificaram. Enfim, as atividades em torno do estudo da natureza possibilitavam uma integração com o mundo social das elites urbanas, principalmente.

No início dessa era moderna, a História Natural não se mostrava uma área de conhecimento especializada, muito embora se perceba uma movimentação de vários setores da sociedade com o intuito de concentrar, de forma mais precisa, informações acerca do mundo natural. Enxergamos, então, que essa interação entre certos personagens - naturalistas, artistas, patrícios ricos, governantes etc. - e suas ações, demonstra que o processo de construção do conhecimento é multifacetado, rico em detalhes e que retrata variados interesses e ideias, ou seja, que se desenvolve dentro de um determinado contexto histórico e sociocultural. Esses são elementos históricos importantes que precisam estar mais presentes nas salas de aula, pois, podem viabilizar um ensino de ciências mais dialogado e reflexivo, especialmente acerca das práticas científicas, como também sobre aspectos relevantes de natureza da ciência. 
Os gabinetes de curiosidades ou quartos de maravilhas também fizeram parte desse processo de constituição da História Natural. Tornaram-se ambientes privilegiados de sociabilidade. As elites urbanas fizeram desses espaços locais de reuniões sobre uma ampla variedade de tópicos, cenários ideais para conversar e constituir uma cultura de erudição. Para isso, os naturalistas coletaram os objetos naturais com a intenção tanto de aumentar seu estoque de observações quanto aprimorar suas declarações sobre as estruturas essenciais que compunham o mundo natural. É importante frisar que esse novo interesse pela cultura material tem uma estreita relação com a realização de viagens de exploração que estavam em ascensão e, particularmente, direcionadas para as "descobertas" da América, da África e da Ásia (Findlen, 2000).

Essas viagens de exploração retratam um momento valioso da história e para a história das ciências. Exibem as performances dos naturalistas, dos artistas, dos patrocinadores para o desenvolvimento e divulgação do conhecimento em História Natural. E as imagens, inseridas nesse contexto, podem nos fornecer evidências sobre esse recorte histórico, bem como subsidiar um debate acerca de aspectos relevantes do conhecimento científico desse período.

A respeito das representações visuais dessa era renascentista, os seus autores alegavam que tinham sido extraídas da vida ou que se tratavam de imagens "vivas". Porém, certos artistas/naturalistas duvidavam do papel e da autenticidade das imagens, ou seja, diziam que as ilustrações não refletiam a natureza e que eram frutos de manipulação, portanto, não contribuíam para o conhecimento. Mas, por outro lado, os desenhos poderiam servir como recursos para memorizar o texto, acentuando esquematicamente certas características ou atributos descritos no texto. Uma imagem também poderia "ilustrar" um pedaço de texto de uma maneira geral. Por fim, havia várias maneiras pelas quais o texto e a imagem estavam relacionados no livro impresso do início da modernidade (Kusukawa, 2000, 2011).

Do mesmo modo, problemas de representação em anatomia foram discutidos em termos da variabilidade do corpo humano, que deveria ser um corpo humano "canônico", um corpo masculino perfeito, desprovido de variações individuais. Aliás, certos estudiosos duvidavam da utilidade das imagens para aprender sobre a anatomia, argumentando, por exemplo, que a anatomia deveria ser praticada pelas próprias mãos e pelos olhos, não apenas olhando superficialmente o corpo, ou seja, como se estivesse olhando uma ilustração (Kusukawa, 2000, 2011).

A mesma autora (Kusukawa, 2000, 2011) relata, ainda, que criaturas fantásticas, como um ser meio humano e meio animal ou um tamboril monstruoso, que eram impressas em folhas soltas como presságios de coisas terríveis por vir, também foram incluídos nas obras de História Natural durante o renascimento. Assim como o unicórnio e a mandrágora tinham uma longa fila de autoridades acadêmicas atestando sua existência, relatos de seres monstruosos ou sobrenaturais, quando provenientes de testemunhas oculares críveis, podiam ser encontrados na literatura acadêmica da natureza. 
Em séculos passados, o contato intenso com terras afastadas possibilitou a difusão de muitas descrições lendárias e, ao mesmo tempo, com pretensões de "rigor científico". Certos textos ilustrados costumavam apresentar humanos e animais "monstruosos". Essas representações propagaram-se em diversas enciclopédias da idade média e em relatos de viajantes durante o renascimento e, também, no iluminismo. Então, essa cultura medieval, que era fascinada pelo "monstruoso", considerado algo maravilhoso ou exótico, perpetuou-se no tempo. Dessa forma, viajantes empenhavam-se no descobrimento de novas terras por estarem atraídos por esse maravilhoso e pretendiam encontrá-lo mesmo onde não existia (Eco, 2015; Scoditti, 2011).

Em síntese, o período entre 1450 e 1600 pode ser definido como um tempo em que não havia consenso estabelecido sobre o que as imagens representavam e como elas poderiam ser usadas para obter conhecimento sobre a natureza, ou seja, a questão da validade das ilustrações na História Natural ainda não se encontrava resolvida no período do Renascimento. Foi um período em que as pessoas experimentavam maneiras diferentes de representar a natureza no papel bidimensional (Costa, 2006; Kusukawa, 2000, 2011), bem como na própria forma de se investigar o mundo natural.

O estudo do mundo natural, a contar do período renascentista, passou por um processo de mudanças em relação à forma como se investiram recursos humanos e financeiros para o seu desenvolvimento, às concepções sobre o estudo da natureza, e à apreciação e à difusão desses conhecimentos. A partir dessa era moderna, maiores esforços tanto de patrocinadores quanto de naturalistas foram exigidos, pois os registros anteriores não eram mais suficientes para explicar todo o material coletado e suas finalidades, bem como interagir com as novas informações adquiridas. Nesse contexto, a História Natural se consolida como uma área de estudo ampla, que buscava acumular, ostentar, conhecer, entender e dominar os elementos da natureza.

A História Natural foi desenhada tanto pela cultura da exibição quanto pela cultura da erudição. Chegando ao século XVIII, essa disciplina mudou-se para os salões, cafés e academias provinciais, locais onde os entusiastas se reuniam para as palestras públicas e apreciavam as histórias naturais mais acessíveis, escritas em línguas vernáculas, que as introduziram em novos sistemas taxonômicos. Nesse novo cenário, naturalistas como Georges-Louis Leclerc, Conde de Buffon (1707-1788), e Carl Linnaeus (1707-1778) estavam preocupados em expandir sua audiência, assim como estudiosos da renascença estiveram preocupados em encontrar uma audiência para seu trabalho. No caso do naturalista sueco, quando reformulou o estudo das plantas no início desse século, renomeando-as, ele não deixou de celebrar os nomes de patronos dignos que avançaram no estudo da História Natural, ou seja, tanto os investidores quanto os estudiosos, que deveriam ser imortalizados na nomenclatura binomial e cujas contribuições Linnaeus considerava significativas. Enfim, os clientes eram tão importantes quanto os naturalistas e, sem esses, a História Natural, situada entre a corte renascentista e o salão do Iluminismo, entre as universidades e as academias, não teria se desenvolvido (Findlen, 2000). 
No século XVIII, a História Natural buscou envolver toda uma gama de formas observáveis, dos minerais ao humano. Seu método era descritivo e seu escopo era enciclopédico. A meta da História Natural era descrever e classificar as formas da natureza. O objetivo dos naturalistas no século XVIII era encontrar um sistema "natural" que identificasse plantas e animais por suas "essências" - ou seja, aquelas coisas que os tornavam o que eram -, pois essa busca por um sistema natural era uma busca pelo plano de Deus. Não havia dúvidas de que as formas de seres vivos estariam relacionadas aos propósitos de Deus em sua criação (Hankins, 2010).

Durante o renascimento, a contemplação da natureza não supria mais as necessidades de quem a admirava, ou seja, o interesse de posse foi despertado e a ostentação de bens naturais, como bens materiais, virou regra. $\mathrm{O}$ exótico e o bizarro tornaram-se objetos de investigação, e a coleção e a exposição da natureza capturada moldaram a História Natural dessa época. Já no iluminismo, essa natureza empossada, aglomerada, precisava de uma organização mais precisa, que facilitasse o reconhecimento de suas propriedades e, consequentemente, a sua divulgação como um conhecimento sistematizado e realizado por pessoas entendidas do assunto. Transformou-se em um campo de conhecimento especializado e com foco na descrição detalhada das características determinantes de plantas e de animais, bem como de minerais, isto é, um conhecimento norteado por um sistema de classificação de seres vivos e de tudo que se encontrava ao seu redor. Além disso, assumiu um viés mais empirista e utilitarista. Todavia, essas investigações, na era ilustrada, buscavam, ainda, explicar ou justificar as obras e ações divinas. Na seção a seguir, discutiremos em profundidade esse assunto.

Do renascimento ao iluminismo, não havia uma concepção única sobre o mundo natural, e sobre as práticas adotadas por médicos, naturalistas e filósofos naturais. Mas, é importante saber que havia uma diversidade de visões de mundo, de práticas nas ciências da natureza e que não é possível apresentar todos os debates, contradições, desacordos que ocorreram entre pensadores daqueles períodos.

Ao nosso olhar, esse conjunto de informações acerca da História Natural ao longo da era moderna pode contribuir para uma compreensão mais ampla sobre as ciências e suas relações com a conjuntura política, social, econômica etc. do período. Em especial, certos elementos-chave que foram apresentados ao longo do texto, como a mudança de perspectiva nos estudos da natureza, o financiamento e os financiadores das pesquisas, a atuação de naturalistas e artistas, a produção das imagens da natureza, a constituição dos gabinetes de curiosidades, podem ser levados à sala de aula, através de ilustrações científicas, como uma oportunidade de ofertar um ensino na interface com a HFSC e que promova reflexões sobre as práticas científicas históricas.

\section{A classificação do mundo natural no século XVIII}

Segundo Prestes (1997, p. 15), “o século XVIII vive o apogeu da História Natural, mais comumente caracterizado pela atenção especial à descrição e classificação dos seres vivos". Parte-se do pressuposto de que para estudar um determinado ser vivo é necessário, primeiramente, observá-lo, descrevê-lo e classificá-lo. Compreende-se, 
ainda, que a classificação (ou a taxonomia) é importante para o desenvolvimento de outras áreas de conhecimento. Os sistemas antigos de classificação dos seres vivos eram construídos a partir da semelhança ou diferença existentes entre os organismos, ou seja, tomava-se como base a forma apresentada pelo ser vivo. Esses padrões de organização remontam à antiguidade grega, principalmente a Aristóteles (Hankins, 2010; Prestes et al., 2009; Santos, 2006).

O sistema de classificação dos vegetais, por exemplo, começou tomando como base as propriedades medicinais, farmacológicas e alimentícias das plantas; houve também a classificação de acordo com a forma de crescimento desses seres vivos, ou seja, foram organizados em árvores, arbustos e ervas; em outros momentos, as características morfológicas dos vegetais, como raízes, caule, folhas, flores foram utilizadas para classificar todas as plantas. Todavia, no século XVIII, a estrutura floral foi escolhida como principal elemento de referência e consolidou um sistema de classificação na época: o sistema sexual de Linnaeus (Santos, 2006).

Para os historiadores naturais compreenderem a multiplicidade de formas naturais, eles deveriam primeiro reduzi-las a algum tipo de ordem ou classificação, arbitrária em certa medida. Poder-se-ia, por exemplo, optar por listar todas as plantas, classificando-as em termos de uma característica essencial, como as partes floridas. Isso poderia ajudar a distinguir entre diferentes formas, mas não descreveria nenhuma forma em sua totalidade. A distinção entre formas de plantas com base em uma única característica seria "artificial" (Hankins, 2010; Prestes et al., 2009).

Portanto, havia grande dificuldade em decidir o que constituía a essência de uma planta ou animal e, consequentemente, quais sistemas de classificação eram "naturais". O problema era se um sistema natural exigia uma única característica ou todo um complexo de características para definir um espécime. Uma única característica, como folha ou caule, poderia, por exemplo, distinguir as formas de uma parte do reino vegetal e falhar completamente em outra parte. Uma alternativa seria subordinar certas características a outras. A forma da flor poderia ser a principal característica diferenciadora; outras características seriam subordinadas a essa principal e usadas para diferenciação adicional entre plantas que possuíam flores semelhantes. Contudo, a decisão de quais características eram dominantes e quais eram subordinadas, e em que ordem, inevitavelmente envolvia uma certa quantidade de arbitrariedade e levantava dúvidas sobre se o sistema era natural ou artificial (Hankins, 2010).

Como a maioria das plantas são hermafroditas, contendo órgãos reprodutores masculinos e femininos, o fato de se reproduzirem sexualmente não era óbvio, e apenas alguns casos eram conhecidos na antiguidade. Rudolph Jacob Camerarius (1665-1721), um estudioso alemão, foi pioneiro na demonstração experimental da sexualidade das plantas, o que forneceu uma base possível para um sistema natural de classificação, pois, para o pensamento da época, o mecanismo de geração deveria, necessariamente, determinar também a forma da planta. Os estudos de Camerarius deram suporte a um sistema anterior, também relevante, de Andrea Cesalpino (1519-1603), naturalista 
italiano que se baseou nas partes das plantas envolvidas na frutificação. Um outro sistema, de Joseph Pitton de Tournefort (1656-1708), botânico francês, apresentava os órgãos reprodutivos das plantas - suas flores e frutos - como as únicas características confiáveis que poderiam formar a base para a classificação. No que se refere aos animais, era notório que os espécimes fossem determinados por sua capacidade de se reproduzir e, portanto, a analogia com as plantas deu mais apoio à noção de que qualquer sistema natural deveria ser baseado nas características reprodutivas dos espécimes (Hankins, 2010).

Outro botânico, John Ray (1627-1705), naturalista inglês, seguiu Cesalpino e os sistematas contemporâneos, mas os métodos da filosofia natural britânica da época o convenceram de que nenhuma característica isolada poderia criar um sistema natural. Assim, durante o Iluminismo, existiram dois campos separados: aqueles que acreditavam na possibilidade de um sistema natural baseado em uma única característica e aqueles que insistiram que era necessário um conjunto amplo de características (Hankins, 2010).

Essas ideias iniciais sobre que parte do organismo deveria ser adotada como elemento estruturador para elaborar um método para classificar um ser vivo são informações relevantes para compreender as bases teóricas que fundamentaram um dos principais sistemas de classificação de seres vivos do século XVIII. Aliás, ajudam a entender os componentes que foram retratados em uma ilustração científica, como também a explicar a estreita relação entre essas ilustrações e as práticas dos naturalistas desse período, como veremos ao longo desse trabalho.

O aprofundamento dos estudos sobre as formas e as funções das diferentes partes das plantas fez surgir novas concepções a respeito da função das flores, que antes estava relacionada à nutrição e eliminação de resíduos dos vegetais, bem como ajudar a formular a ideia da presença dos sexos masculino e feminino nas plantas. Neste contexto estava Linnaeus que, absorvendo as ideias dos seus antecessores acerca da reprodução sexual das plantas, elegeu a flor como o órgão de referência para a classificação. Aliás, percebendo a operacionalidade que o número e a posição de estames e pistilos ofereciam para agrupar as plantas, considerou o número, a proporção e a posição dos estames em relação aos pistilos para definir as 24 classes de plantas (Figura 1). Já o número de estigmas e o formato dos pistilos foram utilizados para estabelecer as ordens, ou seja, as subdivisões das classes (Prestes et al., 2009). 
Figura 1. As 24 classes de plantas do sistema de classificação de Linnaeus, de acordo com o número e a posição dos estames

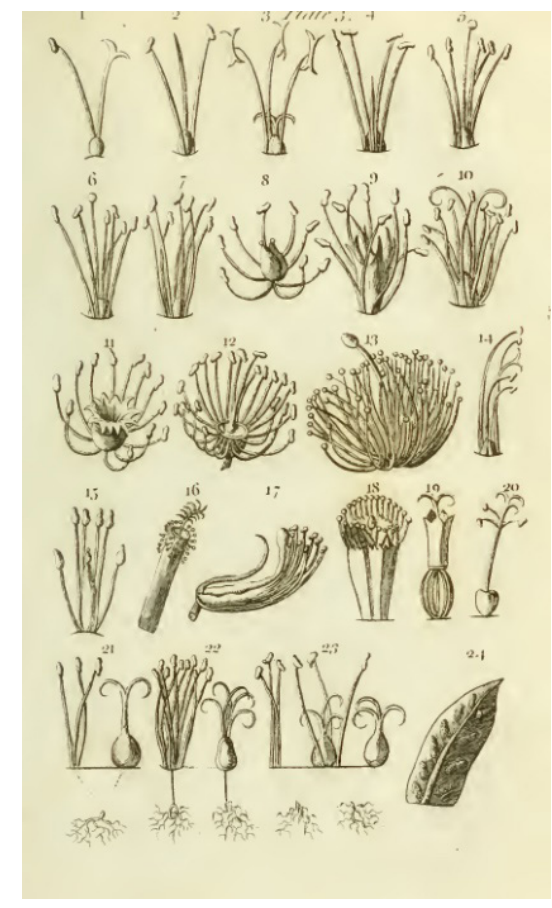

Fonte: Lee (1788).

O debate entre os partidários de uma taxonomia baseada em uma única característica e os defensores de uma taxonomia baseada em um conjunto de características atingiu seu ápice no primeiro volume da História Natural de Buffon. Buffon iniciou seu ataque ao sistema linneano na Academia de Ciências de Paris em 1744, exatamente quando esse sistema estava obtendo aceitação quase universal dos botânicos. Além disso, Buffon criticou não apenas o sistema de Linnaeus, mas todos os sistemas de classificação que dependiam apenas de características externas. Ele acreditava que o universo era composto de objetos individuais. Forçá-los a um conjunto racional de categorias era impor uma abstração artificial da mente humana à natureza. O naturalista francês afirmou que a taxonomia de Linnaeus compartilhava a fraqueza da matemática. Era abstrato, artificial e preciso, porque vinha da mente, não da natureza. A resposta de Buffon foi determinar os espécimes não por nenhuma característica, mas por sua história reprodutiva. Para ele, os membros de qualquer espécime poderiam ser identificados por algumas características físicas, mas essas características deveriam ser apenas propriedades acidentais. Assim, a identificação essencial dos espécimes seria através da história de sua propagação e não a partir de qualquer forma física (Hankins, 2010).

Linnaeus reconheceu que seu sistema não era natural e constantemente tentou melhorá-lo, mas não duvidou que algum sistema fosse necessário para a botânica e que realmente existisse um sistema natural. Na sua opinião, uma classificação artificial e uma 
natural não eram dois esquemas distintos entre os quais alguém era forçado a escolher. Pelo contrário, um estava ligado ao outro, como um meio provisório, mas necessário, para um fim mais perfeito, porém remoto (Hankins, 2010; Koener, 2000).

No "século das luzes", a maioria dos botânicos que trabalhava na Europa baseavase nos princípios do sistema sexual de Carl Linnaeus. Para comunicar informações acerca das propriedades de um espécime vegetal, que era considerado relevante típico e taxonomicamente, adotava-se o sistema de classificação proposto pelo naturalista sueco. Transmitir as propriedades que determinam os espécimes e gêneros linneanos de uma planta, inclusive através de ilustrações científicas, era bastante relevante para os estudiosos desse período (Nickelsen, 2006).

Linnaeus criou uma árvore de classificação global abrangendo todas as formas de vida na Terra, dividindo-as em cinco níveis de aspectos gerais: classe, ordem, gênero, espécime e variação. Ele privilegiou a classificação do gênero e subdividiu os gêneros das plantas de acordo com o número, tamanho, posicionamento e forma do estame e pistilos. Para os animais, ele os agrupou a partir de amplas e variadas características, como dentes, locomoção, tipo sanguíneo e habitat natural (terra ou água). A divisão da fauna de Linnaeus, termo que foi introduzido por ele, assim como flora, foi bastante influente. Ele foi o primeiro a nos chamar de Homo sapiens e nos classificar como primatas. Sua inovação foi conceber uma classificação floral artificial de forma consciente, organizando-a, inclusive, em ordem alfabética (Nickelsen, 2006).

A intenção de Linnaeus era elaborar um sistema novo de classificação. A sua proposta envolvia a organização dos seres vivos de forma que facilitasse a descrição e a unificação dos nomes atribuídos aos diversos tipos e grupos de plantas, animais e minerais conhecidos na época, ou seja, queria propor um sistema padrão, de uso universal. Nesse sentido, ele reuniu ao sistema de classificação uma sistemática de descrição e uma normatização para a nomeação dos espécimes e gêneros. Apresentou definições e terminologias próprias que permitiam uma identificação rápida dos organismos. Subtende-se, ainda, que a simplicidade e a praticidade do sistema de classificação proposto pelo naturalista também podem ter contribuído para a sua gradativa aceitação e expansão pelo mundo (Prestes et al., 2009).

Em 1735, Linnaeus já tinha completado sua teoria sistêmica e, através da sua principal obra, Systema naturae (1735), apresentou uma classificação universal das produções naturais. Sua classificação começou com os espécimes, que ele acreditava estarem fixos desde o tempo da Criação. Agora, restava, apenas, inserir a natureza na sua árvore classificatória. Ele estimou que a Terra abrigava cerca de 40.000 espécimes de plantas e animais e algumas centenas de minerais. Posicionou-se como árbitro final de todas as produções naturais. As primeiras aplicações de seu sistema foram no Flora Lapponica (1737) e no Hortus Cliffortianus (1737). Ao estender sua sistematização, costumava vasculhar a literatura anterior em busca de citações de espécimes e, como método principal, privilegiava a experiência. Porém, ele não fez distinção entre estudos sobre herbário, coleta e viagem. De modo geral, ele era um examinador talentoso e rigoroso da natureza (Hankins, 2010; Nickelsen, 2006). 
O Hortus Cliffortianus, um dos importantes trabalhos de Linnaeus, revela uma suntuosa obra ilustrada sobre plantas cultivadas no jardim de George Clifford, banqueiro de Amsterdã e diretor da Companhia Holandesa das Índias Orientais. Aliás, não foram poupadas despesas para tornar o livro bonito e útil. O patrono rico de Linnaeus contratou os serviços do ilustrador botânico alemão Georg Dionysius Ehret (1708-1770) para preparar os desenhos dos espécimes, as frescas e as secas, e o renomado artista holandês Jan Wandelaar (1690-1759) para gravar os desenhos (Daston \& Galison, 2010).

De forma breve, é importante pontuar que a produção dessa obra linneana, Hortus Cliffortianus, composta por muitas ilustrações científicas, contradiz o que Koener (2000) relata sobre o fato de Linnaeus considerar que as imagens coloridas ou gravadas seriam supérfluas, pois, para ele, o seu sistema sexual dependia apenas de algumas características facilmente observáveis. O interessante é que em outras publicações importantes do botânico, como Philosophia botânica (1751) (Figura 2) e a já citada Flora Lapponica (Figura 3), há, também, uma presença significativa de ilustrações científicas. Nessa direção, entendemos, portanto, que as ilustrações não estavam à margem dos trabalhos dos naturalistas do período em destaque, muito menos nas obras do próprio Linneaus.

Figura 2. Ilustrações de partes florais encontradas na obra Philosophia botânica de Linnaues

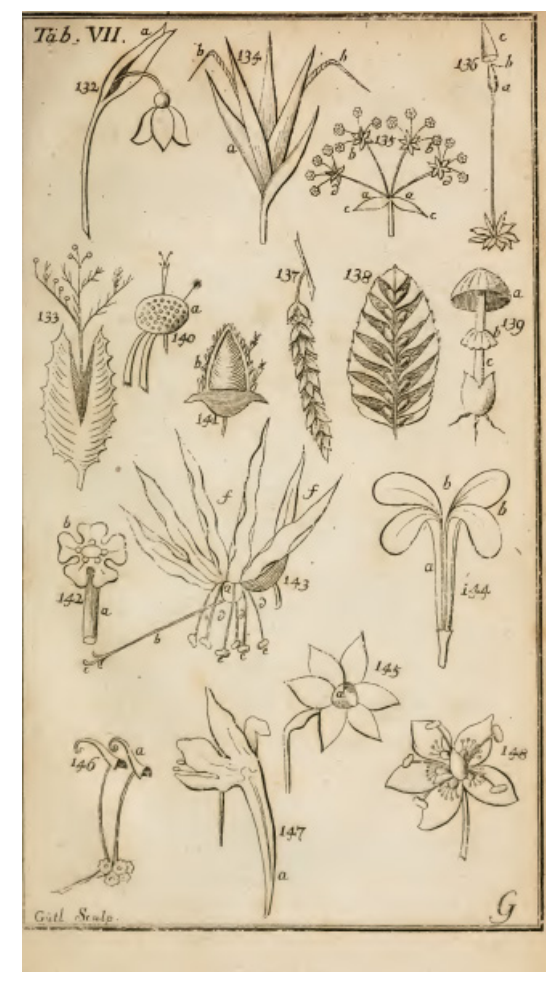

Fonte: Linnaei (1751). 
Figura 3. Exemplo de ilustração botânica encontada na obra Flora Lapponica de Linnaeus

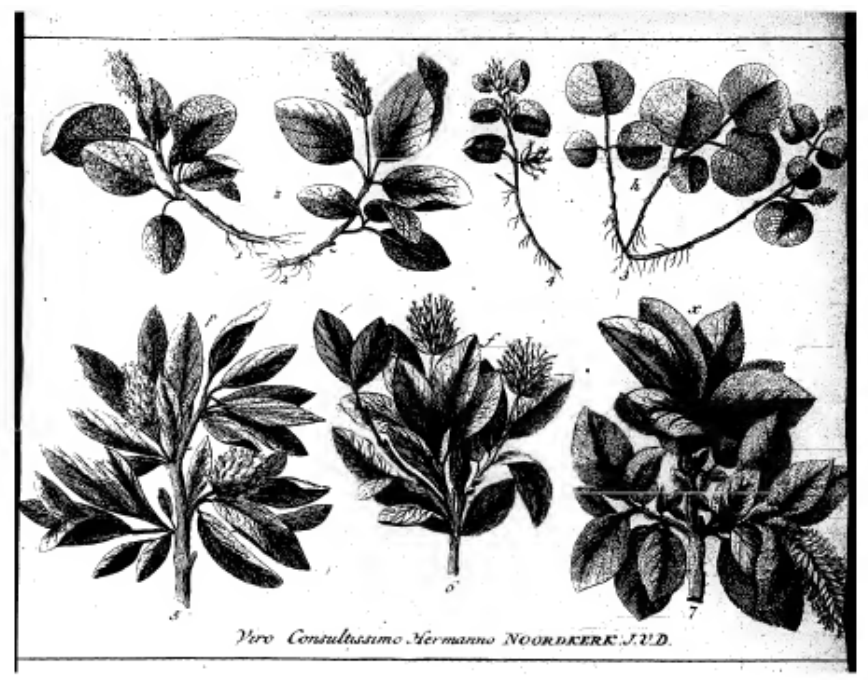

Fonte: Linnaei (1737).

A respeito do alcance das propostas de Linnaeus, cabe ressaltar que até os estudantes pobres e pessoas comuns também poderiam se tornar botânicos competentes (algo não muito comum para à época), e uma biblioteca cara e instruções antigas não eram mais essenciais para o treinamento de um botânico. Por exemplo, ele nomeou plantas para mulheres, agricultores, artesãos etc. como forma de incentivo para ingressarem nos estudos botânicos. Descreveu práticas botânicas para ajudar os iniciantes. Produziu guias botânicos, com instruções que ensinavam o leitor como montar um herbário, organizar uma excursão, plantar um jardim e até embarcar em uma viagem de descoberta. Alguns desses exemplares apresentavam desenhos esquemáticos de peças de plantas, além de vários índices (Koener, 2000), diferentemente dos outros trabalhos, que já foram citados anteriormente.

Koener (2000) também relata que os primeiros botânicos modernos, inclusive Linnaeus, construíram uma classificação taxonômica que envolvia uma breve descrição do espécime, que funcionava simultaneamente como um nome próprio. Esses nomes tinham até meia página e variavam de autor para autor. Mas, por volta de 1740, na Universidade de Upsala, diante da dificuldade de usar a nomenclatura da classificação taxonômica vigente, Linnaeus e seus alunos começaram a criar termos abreviados e a experimentar formas práticas e comuns para se referir a um espécime, e, entre 1748 e 1749, Linnaeus e seus alunos começaram a usar o que hoje conhecemos como binômios verdadeiros. Estes apareceram pela primeira vez em Pan Svecicus (Figura 4), um breve trecho sobre forragem de gado, publicado em 1749. Mais tarde, os binômios se espalharam dos panfletos econômicos de Linnaeus para seus Tomos classificatórios. 
Figura 4. Exemplo da apresentação da nomenclatura binominal de Linnaeus em Pan Svecicu

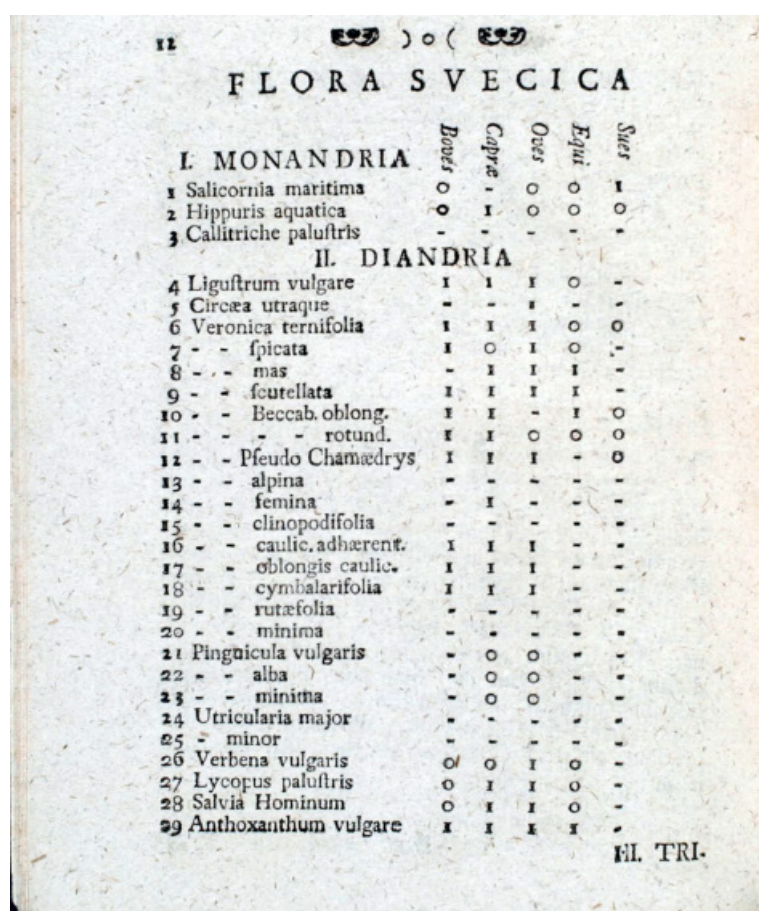

Fonte: Linnaeo (1749).

Então, em uma das suas obras, Philosophia botanica (1751), Linnaeus sugeriu que cada forma de vida fosse rotulada com um "nome comum", ou uma referência de duas palavras, denotando seu gênero e espécime, ou seja, uma nomenclatura binomial. E a partir do Species plantarum de Linnaeus (1753) e do Systema naturae (10a ed., 1758), muitos nomes de plantas e animais, entre outros organismos, foram gerados. Philosophia botanica e a nomenclatura binomial recomendada foram recebidas com entusiasmo. Reimpresso dez vezes em latim, entre 1755 e 1824, o livro também foi traduzido para inglês, holandês, espanhol, alemão, francês e russo. Inúmeros dicionários botânicos também foram publicados. Eles foram modelados no vocabulário vegetal de Linnaeus em Termini botanici (1762). Na década de 1760, em toda a Europa, floras locais, publicações de placas botânicas, histórias naturais de países estrangeiros e até monografias de espécimes e livros infantis, usavam o vocabulário linneano (Koener, 2000).

As investigações de Linnaeus buscavam atender às necessidades econômicas do Estado e suas viagens e coletas foram realizadas em parte por razões econômicas. Portanto, para ele, o viajante ideal deveria ser um espião industrial nas cidades ocupadas das altas civilizações e não um andarilho solitário em um mundo natural intocado. Com essa sua prática, Linnaeus conquistou um papel lucrativo como consultor governamental em viagens, coletas e economias coloniais. Inclusive, concederam a ele o direito de dispor de sua cadeira da universidade e ratificaram a recomendação do rei de enobrecer Linnaeus. Assim, Linnaeus comprou uma propriedade rural, garantiu a sucessão de seu filho e foi apelidado de "von Linné" (Koener, 2000). 
É importante frisar que, no século XVIII, havia outros estudos referentes à classificação de seres vivos, que foram realizados por outros naturalistas. Mas, adotamos a historiografia relacionada com a proposta de Linnaeus devido à audiência que teve no período, e que ainda tem atualmente, muito embora, na educação básica, seja uma perspectiva trabalhada, em grande parte, de forma descontextualizada. Dito isto, buscamos elencar, na próxima seção, as principais características das ilustrações científicas, tratando com mais detalhes o papel das ilustrações científicas no processo de classificação de plantas e animais desse período iluminista, que tomou a proposta de Linnaeus como mais representativa.

\section{As ilustrações científicas e o seu papel no sistema de classificação do mundo natural no século XVIII}

No final do século $\mathrm{XV}$, os desenhos foram perdendo o esquematismo característico das gravuras e começaram a manifestar elementos mais naturalísticos e "precisos" do objeto retratado. Chegando ao século XVIII, muitas imagens novas e consideradas realistas passaram a ser mais requisitadas e, portanto, inseridas nas obras dos naturalistas para dar mais "valor científico" aos volumes. Buscava-se, por exemplo, preencher uma lacuna entre o conhecimento textual da natureza e a experiência com ela, bem como atender as demandas dos próprios naturalistas e do mercado editorial (Swan, 2011).

Os estudos independentes de artistas e naturalistas sobre o mundo natural e o desenvolvimento da representação mais naturalista e de técnicas que buscavam uma reprodução "precisa" da natureza também viabilizaram o aprimoramento do valor comunicativo dos textos ilustrados. Nesse sentido, a participação de impressoresempreendedores foi fundamental para o processo de construção do conhecimento sobre a natureza. Aliás, os vários interesses inseridos na produção das imagens (influências sociais, cognitivas, intelectuais etc.) contribuíram bastante para o desenvolvimento do conhecimento natural nesse período moderno (Smith, 2006).

Considera-se que o aumento na produção de ilustrações científicas, no período iluminista, teve estreita relação com a expansão das investigações em botânica. As plantas eram mais fáceis de serem estudadas - devido aos limites de locomoção - , classificadas e, consequentemente, ilustradas, e as peças secas de plantas não atendiam as mesmas funções do desenho, que tornava visível "não aquilo que é visto, mas antes aquilo que deve ser visto" (Sicard, 2006, p. 95), ou seja, através da ilustração se destacavam as características de uma determinado espécime, que eram difíceis de serem percebidas através do exemplar natural (Musch, 2017; Scoditti, 2011; Sicard, 2006).

Mergulhadas em um contexto de descoberta do novo mundo, as ilustrações científicas do século XVIII tornaram-se não apenas evidência do curioso, do maravilhoso e do particular, mas também um importante instrumento de registro, de coleta, de catalogação. Nesse caminho, surgiu uma "nova estética", estabelecendo uma demanda por representação "realista" que, combinada com os diversos fatores de exploração (de novos territórios, de comércio, de recursos naturais etc.), instituiu uma cultura de descrições tanto de testemunhas oculares quanto de representação (Smith, 2006). 
Partimos do pressuposto de que essa "nova estética" se tornou um padrão de ilustração científica adotado e confirmado entre os sábios iluministas e pode ser chamada de uma representação "fiel à natureza". Subtende-se que foi uma reação à ênfase dada pelos primeiros naturalistas à variabilidade e à monstruosidade da natureza. Todavia, o naturalista e o artista iluministas concebiam a fidelidade em termos do exercício de julgamento fundamentado na seleção de imagens "típicas", "características", "ideais", isto é, todas seriam variedades da imagem fundamental. A principal tarefa era determinar o que era essencial. Na visão desses profissionais, qualquer mérito que essas imagens visuais tivessem derivava precisamente desse discernimento e da amplitude e profundidade da experiência nas áreas sobre as quais esse discernimento se assentava (Daston \& Galison, 2010).

Daston e Galison (2010) sugerem, ainda, que as tentativas do século XVIII para superar a variabilidade extravagante da natureza eram muitas vezes reforçadas por uma versão iluminista da teologia natural, que se caracterizava por louvar a regularidade das leis divinas como mais digna de admiração do que a maravilha ou o milagre excepcional. Portanto, o "fiel à natureza" surgiu em determinado momento e local e tornou possível um tipo particular de ciência - uma ciência mais das regras do que das exceções da natureza.

Nessas ilustrações científicas do século XVIII, os fenômenos “típicos” eram aqueles que remontavam a algum Typus ou "arquétipo" subjacente, e dos quais derivavam, pelo menos conceitualmente, os fenômenos individuais. Essas imagens típicas predominam nos atlas anatômicos, botânicos e zoológicos desde o século XVII até meados do século XIX (e às vezes estendem-se por tempos seguintes), mas nem sempre em uma forma isenta de misturas. E duas variantes importantes, chamadas de "ideal" e "característica", também aparecem em ilustrações deste período. A ilustração "ideal” pretende representar não apenas o típico, mas, antes, o perfeito, enquanto a ilustração "característica" busca o típico em um indivíduo. Tanto as ilustrações ideais quanto as características regularizam o fenômeno, e os fazedores de ambos insistiam na precisão do desenho. Então, na perseguição do "fiel à natureza", imagens deveriam ser escolhidas, a partir do melhor padrão existente na natureza, com todas as suas partes belas e agradáveis de se olhar e de se mostrar um exemplar. Por fim, o universal deveria ser representado em uma determinada imagem, a imagem fundamental (Daston \& Galison, 2010).

Para atender tais requisitos, os naturalistas ansiavam por artistas com conhecimento. Então, alguns desses naturalistas chegaram ao ponto de treinar seus próprios artistas quando ainda crianças, para lhes formar o estilo de forma completa. Ao final, a imagem fundamental tinha autoria: sintetizada, tipificada, idealizada pelo intelecto do naturalista. Mas, para passar essa imagem fundamental para o papel, o artista tinha de se tornar algo mais próximo de um meio do que meramente um subordinado (Daston \& Galison, 2010), o que exprime, portanto, o protagonismo dos artistas nesse processo de confecção das ilustrações científicas. 
Através das viagens ultramarinas, buscava-se o reconhecimento das riquezas naturais (animais e vegetais) e minerais, bem como suas utilidades econômicas. Essas propostas eram sinalizadas pela elite naturalista europeia, que tinha como integrantes, por exemplo, o naturalista já citado, Linnaeus, e o italiano Domenico Vandelli (17351816), naturalista contratado pela coroa portuguesa para ajudar a reformular as pesquisas desse país. Assim, a ilustração científica, que estava inserida nesse contexto de exploração do novo mundo, deveria permitir fazer uma leitura à distância que possibilitasse o conhecimento aprofundado sobre o objeto descoberto por toda a comunidade acadêmica ou atender àquelas pessoas pertencentes à hierarquia política e econômica, que, por motivos específicos, não estavam presentes no local. Havia um caminho a ser seguido: desenvolver um trabalho rigoroso, que atingisse "a exatidão informativa, seguindo linguagens internacionais e as convenções impostas pela sistematização científica e as suas respectivas instruções" (Faria, 2001, p. 38).

Em suma, as viagens de exploração levaram não apenas naturalistas para descrever, mas também artistas para desenhar a nova flora e fauna. As ilustrações científicas ficaram quase sempre mais intactas do que os espécimes de herbário seco ou animais mortos imperfeitamente preservados, que eram enviados de volta para as coleções. Muitas vezes, serviam aos naturalistas de gabinete como os únicos exemplares dos novos gêneros e novos espécimes. Aliás, complementam as coleções de espécimes naturais, suprindo lacunas e compensando qualquer deficiência acerca do visual do acervo. Serviram, por fim, à causa da memória, pois são mais vivas e indeléveis do que as palavras (Daston \& Galison, 2010; Musch, 2017).

A ilustração científica, no século XVIII, obteve reconhecimento pela sua capacidade de comunicação e pelo seu conteúdo informativo e instrutivo, bem como foi muito valorizada devido ao seu papel didático e documental, e ganhou impulso, principalmente, a partir da imprensa adaptada e com a evolução da reprodução gráfica. A ilustração científica, nesse século, foi além do campo simbólico e religioso, bem como das funções plásticas. Acompanhou o desenvolvimento do "espírito científico" da época, que buscava apreender empiricamente a natureza e seus fenômenos (Faria, 2001).

Faria (2001) também argumenta que, nesse século, as obras dos "desenhadores" europeus de História Natural estavam inspiradas nos "princípios enciclopedistas" e das "luzes consagradoras das artes do desenho", consideradas fontes de desenvolvimento e de progresso. Neste sentido, os "riscadores" eram orientados a fazer um "registro rigoroso" sobre o que estava destinado a observar, ou seja, a produção artística deveria obedecer a orientações acadêmicas e políticas, inclusive sob uma disciplina militar.

No que se refere às ilustrações para fins de estudos de plantas e animais, foram elaboradas com o objetivo de registrar novos espécimes e/ou conhecer detalhadamente o processo de reprodução dos organismos, inclusive dos já conhecidos. Assim, os espécimes, inclusive os exóticos, ou eram retratados de forma isolada do seu habitat, ou, em certos casos, havia uma preocupação em reconstituir, na mesma imagem, o ciclo de vida de um determinado espécime, bem como apresentar notas explicativas manuscritas pelos naturalistas responsáveis pela coleta do material (Faria, 2001). 
A botânica foi o campo de maior interesse para a ciência, a política e a economia dessa época, o que justifica o imenso volume de ilustrações de plantas que foram confeccionados durante as expedições portuguesas e espanholas, por exemplo. A investigação em botânica implicava automaticamente na confecção de desenhos. Apenas quatro variáveis eram consideradas para classificar as plantas naquele período: forma dos elementos, quantidades desses elementos, maneira como se distribuem no espaço (uns em relação aos outros) e grandeza relativa de cada um. Estas variáveis eram exigidas nas ilustrações científicas como forma de viabilizar a classificação do espécime. No que se refere à zoologia, podem ser encontradas algumas tentativas de ambientação, exibindo os seus hábitos alimentares, bem como exprimir cenas do habitat do animal e de ações naturais (Pataca, 2005).

Os argumentos apresentados anteriormente trazem uma síntese das ideias propostas para confeccionar uma ilustração científica no século XVIII. Narram o que deveria ser retratado em uma ilustração, como essa imagem deveria ser feita, quem participava desse processo, enfim, descrevem certos princípios para a produção dessas imagens, bem como a relação entre naturalistas e artistas. Esses elementos são muito importantes para ajudar a compreender o desenvolvimento dessas ilustrações científicas e o seu papel nos estudos da natureza durante o iluminismo, e, consequentemente, abrem um espaço para dialogar sobre as práticas científicas desse período.

$\mathrm{Na}$ Figura 5, por exemplo, podemos observar certos elementos característicos em uma ilustração científica que foi elaborada no século XVIII, no contexto da viagem de exploração ao Brasil comandada por Alexandre Rodrigues Ferreira e com a participação dos artistas Joaquim José Codina e José Joaquim Freire: expressão nítida do recurso natural, ou seja, um desenho que permitiria a rápida identificação do animal (do espécime); presença de cores marcantes; pigmentação característica; destaque de algumas estruturas do peixe, como as barbatanas e os raios; espécime desenhada de lado e centralizada. Eram desenhos de excelente qualidade informativa e estética, e, de acordo com Costa (2006) e Faria (2001), testemunho único do olhar europeu sobre o Novo Mundo.

Figura 5. "Pacu-Piranga do Rio Negro". Desenho realizado por José Joaquim Freire e pertencente ao espólio da Viagem Filosófica de Alexandre Rodrigues Ferreira (1783-1792). Aquarela sobre papel. Dimensão original: $26,5 \mathrm{~cm} \times 16,7 \mathrm{~cm}$

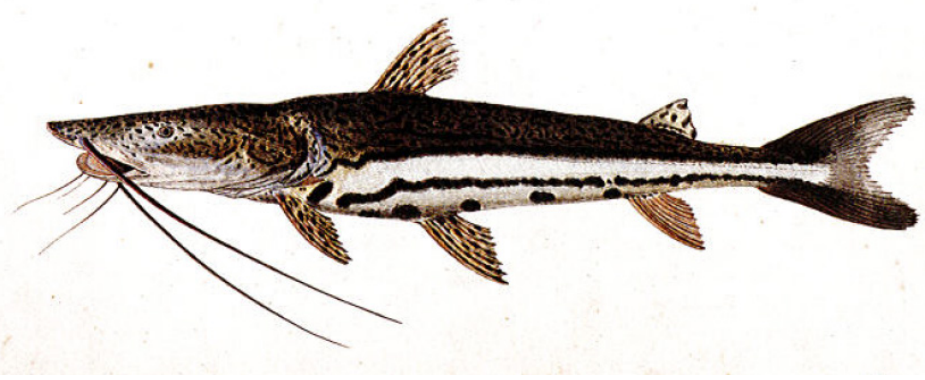

Fonte: Faria (2001). 
Outro ponto que merece destaque é a desvalorização, por parte dos naturalistas e editores, de obras sem ilustrações científicas ou com reproduções sem precisão, ou seja, as publicações em História Natural tinham como uma das exigências a inserção de desenhos bem feitos de espécimes naturais bastante conhecidos ou exóticos, principalmente daqueles organismos, fossem plantas ou animais, que não poderiam ser transportados ou retirados/coletados do seu habitat natural. Por fim, a ilustração científica tornou-se um instrumento essencial ao trabalho dos naturalistas/artistas.

A ilustração seguinte (Figura 6) é mais um exemplo de uma ilustração científica do século XVIII, que teve a proposta de retratar o espécime natural de interesse, valorizando alguns dos seus hábitos e expondo um pouco do seu habitat. E na direção do que foi sinalizado anteriormente, a função plástica é um elemento que também está muito presente, através de contornos bem elaborados e com a expressão de muitos detalhes. Essa ilustração também foi confeccionada durante a viagem de exploração ao Brasil.

Figura 6. "Periquito das Serras do Rio Branco". Desenho realizado por José Joaquim Freire e pertencente ao espólio da Viagem Filosófica de Alexandre Rodrigues Ferreira (1783-1792). Aquarela sobre papel. Dimensão original: $17 \mathrm{~cm} \times 26,8 \mathrm{~cm}$

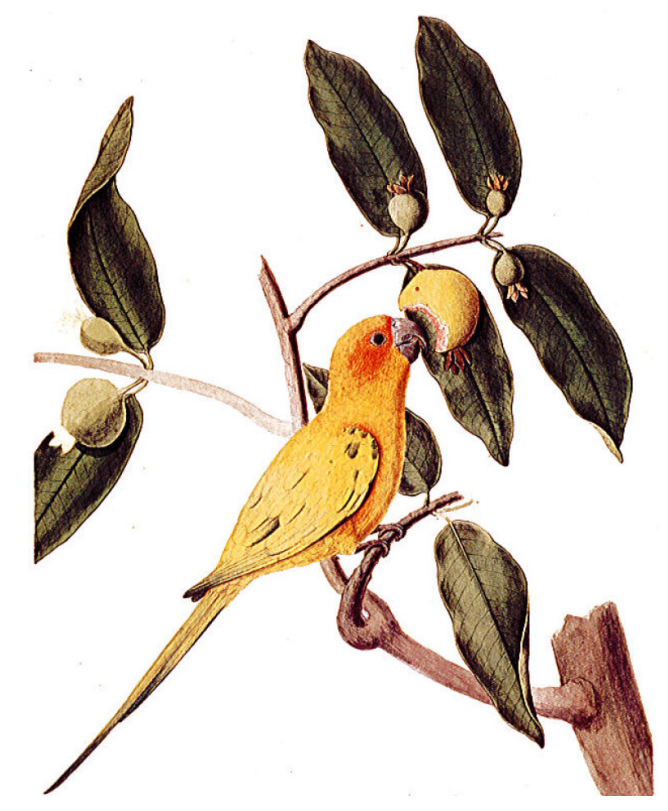

Fonte: Faria (2001).

Conforme exposto, a confecção dessas ilustrações científicas exigia uma equipe composta por naturalista e artista, e até militares, pois, dessa forma, seria possível atender a uma demanda de produção de iconografia documental rigorosa. Tal equipe de trabalho atendia às necessidades de uma formação teórica e prática, com capacidade de selecionar os objetos, classificar, desenhar, saber a localização geográfica, entre outras aptidões. E, mesmo havendo algumas exceções, prevalecia o trabalho coletivo (Faria, 2001). Segundo Daston e Galison (2010), todos os participantes nessa aventura patronos, naturalistas e artistas - pretendiam marcar uma época na História Natural. 
Reconhecemos, portanto, que uma ilustração científica não é uma produção neutra. No século XVIII, entendida como uma imagem "fiel à natureza", buscava atender aos propósitos dos naturalistas e de seus patrocinadores e, além de apresentar uma certa plasticidade, deveria conter os principais elementos característicos de um determinado espécime, portanto, certas estruturas deveriam ser realçadas ou anuladas para permitir a identificação do ser vivo retratado. As técnicas que foram desenvolvidas para a elaboração desse tipo de imagem e a forma do trabalho em equipe, especialmente entre naturalista e artista, são, também, parâmetros que nos permitem traçar um perfil que foi assumido nesse século e que estamos tratando como "fiel à natureza". Neste sentido, esse viés do "fiel à natureza", que se estabeleceu durante o período iluminista, retrata um valor de época e exprime uma marca do seu período histórico.

É importante destacar também que a produção de uma ilustração científica buscava atender aos interesses do Estado, principalmente para a difusão da política e da economia do país, ou seja, através das ilustrações científicas, tornava-se possível, por exemplo, organizar informações sobre como utilizar certas plantas na agricultura, na produção de matérias-primas para a indústria, para a farmácia e para a medicina. Além disso, a ilustração compreendia uma forma de registro de ocupação de território. A ilustração científica foi um dos recursos utilizados para marcar territórios, um registro original e oficial das "descobertas" (Faria, 2001).

Então, para atender tais propósitos, as imagens deveriam ser produzidas in loco, na tentativa de superar práticas "antigas" de representação, como aqueles desenhos que eram feitos por artistas que nunca haviam saído do país de origem e que se baseavam, apenas, em testemunhos de viajantes, levando, muitas vezes, à execução de imagens fantasiosas (Faria, 2001). Percebe-se, portanto, que essa exigência de produção de imagens pode ter contribuído para essa vertente de representação "realista" do objeto observado, ou seja, uma imagem "fiel à natureza".

Segundo Nickelsen (2006), a utilização de ilustrações para transmitir as propriedades que determinavam os espécimes e os gêneros linneanos da planta tornouse um hábito comum entre os botânicos no século XVIII. Para tanto, era exigido conhecimento no assunto para representar essas propriedades, ou seja, era preciso ter entendimento sobre as características da flor e do fruto que determinava uma classe, ordem e gênero da planta. Então, para estar inserido no sistema de classificação linneana, sistema predominante na época em destaque, todos esses aspectos tinham que ser levados em consideração. A produção exigia mais habilidades do que observar e documentar a natureza. Além de talento artístico e habilidades básicas de desenho, era necessário estar familiarizado com as convenções pictóricas específicas do gênero e ter capacidade de aplicar um conhecimento completo de teoria botânica.

O modo como a planta era representada deveria ser decidido inteiramente pelo botânico: detalhes do fruto e das sementes tinham que ser integrados, uma vez que revelavam as características essenciais dos espécimes. Além disso, cada espécime deveria ser desenhado em uma folha de papel individual. Mas, quando houvesse variações na cor 
das flores seria aceitável colocar duas plantas juntas, no entanto, as plantas deveriam ser desenhadas separadamente, a fim de apresentar a morfologia das variantes individuais tão claramente quanto possível. Não se aceitavam plantas decorativamente entrelaçadas umas às outras, embora fosse um outro método popular de composição utilizado também no século XVIII. Enfim, o botânico não apenas tinha que ensinar seu desenhista como produzir um desenho "cientificamente" utilizável, mas também tinha que lhe fornecer uma introdução à teoria botânica. Portanto, era bastante comum, no século XVIII, os desenhistas botânicos passarem, primeiro, por uma formação geral como desenhista (em uma academia ou oficina de membros da família ou outros mentores) e, depois, eram introduzidos por um botânico às demandas específicas dos desenhos de plantas (Nickelsen, 2006).

Após a aceitação da nomenclatura binominal linneana para plantas e animais, muitos nomes usados nas obras botânicas e zoológicas, que foram produzidas anteriormente, tornaram-se obsoletos, porém, muitos desses trabalhos, notadamente aqueles com ilustrações, permaneceram importantes e essenciais para a interpretação de espécimes linneanas e a correta aplicação dos nomes linneanos para organismos já conhecidos (Stearn, 1966).

Nessa direção, consideramos as ilustrações científicas como parte integrante das práticas dos naturalistas. Os argumentos apresentados até este ponto revelam que as ilustrações foram utilizadas para identificar estruturas consideradas relevantes de um espécime, para representar certas características distintivas de um ser vivo e como um meio de comunicação e difusão de conhecimentos sobre animais e plantas. Portanto, as ilustrações científicas não foram apenas úteis para o processo de classificação do mundo natural do século XVIII, mas também se tornaram fundamentais para os estudos taxonômicos do período.

Encontramos, por exemplo, no Diccionario dos termos technicos de História Natural: extrahidos das Obras de Linnéo, com a sua explicaçaõ, e estampas abertas em cobre, para facilitar a intelligencia dos mesmos: e a Memoria sobre a utilidade dos jardins botanicos: que offerece a Raynha D. Maria I. Nossa Senhora, obra publicada em 1788 pelo naturalista italiano Vandelli (1735-1816), a descrição de estruturas morfológicas consideradas mais importantes para o (re)conhecimento de um determinado animal. Sabemos que se trata de um trabalho de tradução do Systema Naturae de Linnaeus, mas percebemos que esses elementos diagnosticantes são representados visualmente nesse material, o que nos faz pensar sobre a pertinência de produzir e utilizar as ilustrações para aprender e apreender sobre as características dos seres vivos e, consequentemente, sua classificação.

Por último, constatamos que para produzir e divulgar conhecimentos havia muito mais que a realização de práticas experimentais, laboratoriais ou de observação. O processo de construção do conhecimento em História Natural envolveu diferentes métodos e utilizou vários recursos para o seu desenvolvimento, bem como contou com a participação de diversos personagens. Nesse sentido, enxergamos as ilustrações científicas 
como fontes históricas de pesquisa, que também são relevantes para investigarmos certos costumes, estilos, valores, concepções e procedimentos relacionados com os estudos da natureza.

\section{Ilustrações científicas históricas e o ensino de ciências: algumas considerações}

Naárea de ensino de ciências, são poucas as pesquisas que utilizam as imagens como objeto de investigação ou que lidam com ilustrações científicas, tal como caracterizadas por nós nesse artigo. Em número ainda menor são os trabalhos que buscam um diálogo entre ilustrações científicas históricas e o ensino de ciências da natureza. De modo geral, nota-se que as imagens são utilizadas, principalmente, como recursos motivacionais e/ ou como "ponto de partida" para uma discussão a respeito de um determinado tema a ser explorado em sala de aula, bem como são raras as pesquisas que sugerem discussões de assuntos metacientíficos a partir do próprio recurso visual. Percebe-se, aliás, que os estudos com imagens estão mais voltados a descrições e narrativas de certas percepções dos estudantes sobre a figura do cientista e/ou sobre outros aspectos relacionados com a vida dos discentes e/ou docentes em formação, e em analisar imagens em livros didáticos (Vitor \& Martins, 2020).

À vista disso, ressaltamos que o nosso trabalho busca trazer uma contribuição específica para a área de ensino de ciências, que se distingue dos demais pelo recorte e pela proposta que o texto apresenta. Por outro lado, é importante destacar que há diferentes pesquisas de historiadores brasileiros sobre imagens na história das ciências, incluindo, por exemplo, obras de arte sobre as práticas médicas, as práticas experimentais, a fauna ou a flora e outros trabalhos de interface.

Em nossa análise, esse estudo historiográfico acerca das ilustrações científicas do século XVIII propicia uma via interessante para discutir sobre aspectos relevantes de $\mathrm{NdC}$ e problematizar as práticas científicas no ensino. Ao que tudo indica, aliás, as ilustrações científicas históricas correspondem a instrumentos pertinentes de investigação histórica sobre as ciências da natureza e podem, ainda, viabilizar um ensino mais crítico e reflexivo sobre as ciências.

Não se deve esperar que estudantes, professores ou futuros professores se tornem historiadores competentes, sociólogos ou filósofos da ciência. Mas, é importante que cada docente esteja comprometido em ofertar um ensino de ciências mais problematizador, que promova um pensamento crítico e reflexivo de forma mais ampla. Para isso, considera-se pertinente apresentar aos alunos os diferentes "pontos de vista" relacionados com o processo de construção da ciência e encorajá-los a raciocinar sobre os assuntos científicos (Matthews, 1998).

Especialistas da área de ensino de ciências acreditam na importância de se aprender sobre a $\mathrm{NdC}$ (NOS, em inglês), para além dos conteúdos científicos. Um indivíduo alfabetizado cientificamente precisa saber tanto sobre conteúdos da ciência quanto a respeito de sua natureza - produção, evolução, avaliação, difusão, relações com o contexto (Bejarano et al., 2019). 
Há uma vasta literatura que discute a respeito de $\mathrm{NdC}^{3}$, mas, de modo geral, a $\mathrm{NdC}$ deve ser entendida como "um conjunto de saberes ou olhares metateóricos que trata dos vários aspectos da atividade científica, seja do ponto de vista internalista (seus métodos e suas teorias), seja em seu caráter eminentemente cultural e social" (Bejarano et al., 2019, p. 968). Já Moura (2014) argumenta que a NdC está relacionada com elementos que tratam da construção, estabelecimento e organizando do conhecimento científico, o que envolve investigar questões sobre fatores internos, como o método científico, e fatores externos, como a influência social, cultural, política, entre outras, na ciência e vice-versa. Em suma, é discutir sobre valores epistêmicos e não epistêmicos da ciência (Gandolfi, 2019; Moura, 2014).

Nessa direção, portanto, procuramos apontar, nessa seção, alguns aspectos relevantes de $\mathrm{NdC}$ que foram identificados a partir do contexto histórico e sociocultural de produção das ilustrações científicas relacionadas com o processo de classificação do mundo natural do século XVIII, tomando como base o trabalho de Martins (2015), que oferece uma abordagem por meio de "temas" e "questões" de NdC.

De acordo com esse referencial, "temas" e "questões" podem ser trabalhados a partir de dois eixos principais: o "eixo histórico e sociológico" e o "eixo epistemológico". No primeiro eixo, sugere-se "temas" relacionados, por exemplo, com o papel do indivíduo e da comunidade científica, com as questões morais, éticas e políticas, com as influências históricas e sociais etc. No segundo eixo, os "temas" apontados referem-se à origem do conhecimento, aos métodos, práticas, procedimentos e processos da ciência e ao conteúdo/natureza do conhecimento produzido.

Assim, tentamos construir um diálogo entre certos "temas" de NdC identificados em nosso estudo historiográfico e o referencial já sinalizado, como uma maneira de viabilizar debates sobre aspectos relevantes de $\mathrm{NdC}$ e, consequentemente, possibilitar uma melhor compreensão sobre as práticas científicas históricas. Para demonstrar essa interlocução, alguns elementos do nosso trabalho foram resgatados e serão apresentados, resumidamente, a seguir.

A exigência de se compor uma equipe de trabalho com diferentes profissionais, como naturalistas, artistas, militares e até patrocinadores, ou seja, pessoas que deveriam ter formação teórica e prática e com competência para selecionar os objetos, classificar, desenhar, saber a localização geográfica de um território a ser explorado e divulgar o conteúdo organizado, entre outras aptidões, enfim, requisitos para confeccionar uma ilustração científica no século XVIII, retrata não apenas um contexto de trabalho que era realizado em conjunto, mas também exprime a importância de cada especialista na construção desse tipo de conhecimento. Nesse recorte, portanto, podemos identificar $o$ papel dos naturalistas e dos artistas e a relação entre história natural e literatura como

3 Há pesquisadores que defendem uma abordagem a partir de uma visão consensual (VC) de NdC, ou seja, trabalham com uma lista de aspectos ("princípios") consensuais acerca da construção do conhecimento científico, que consideram relevantes para o ensino de ciências; por outro lado, há aqueles que criticam esses pressupostos e apresentam uma abordagem alternativa a essa VC de NdC. Não é intenção do nosso estudo adentrar nessa discussão. 
“temas" relevantes para problematizar tanto o envolvimento de vários personagens no desenvolvimento de um estudo investigativo no século XVIII quanto a interação entre os vários tipos de conhecimentos sistematizados nessa época. A título de exemplo, esse cenário se aproxima com determinados "temas" de $\mathrm{NdC}$ que foram sugeridos por Martins (2015), como: "Papel dos indivíduos/sujeitos e da comunidade científica" e "Ciência e outros tipos de conhecimento", respectivamente.

A partir do nosso estudo sobre as ilustrações científicas, torna-se possível, também, discutir sobre as "influências externas" no processo de construção do conhecimento do século XVIII e vice-versa, isto é, problematizar as várias conexões com o ambiente "externo" às atividades dos naturalistas. Relembramos, inclusive, que o trabalho está mergulhado na história e na cultura do período iluminista. Portanto, podese debater sobre fatores históricos e socioculturais, bem como questões éticas e políticas etc., que contribuíram para a imensa valorização e utilização das ilustrações científicas nos diversos campos de conhecimento, especialmente na história natural do período sinalizado. Em Martins (2015), encontramos semelhança com as seguintes propostas de "temas": "Influências históricas e sociais" e "Questões morais, éticas e políticas".

De forma mais abrangente, a "ciência" se tornou uma prática valorizada pelo movimento iluminista e pela burguesia em ascensão. Então, as ilustrações científicas produzidas dentro desse contexto do século XVIII permitiriam refletir sobre a ciência como parte de uma cultura mais ampla. Além desses, os objetivos dos estudos da natureza, os objetivos dos naturalistas e dos órgãos envolvidos no processo de investigação dos recursos naturais também são "temas" de NdC interessantes, pertinentes e que podem ser explorados a partir das ilustrações científicas e do seu contexto de produção e utilização no "século das luzes". Inclusive, constatamos "temas" de $\mathrm{NdC}$, apontados por Martins (2015), que viabilizam reflexões nessa direção. A saber: "A ciência como parte de uma cultura mais ampla" e "Objetivos da ciência / objetivos dos cientistas".

A ilustração científica foi reconhecida pela sua capacidade de comunicação e pelo seu conteúdo informativo, instrutivo, e foi muito valorizada devido ao seu papel didático e documental. Serviu tanto aos naturalistas quanto aos seus patrocinadores. Atendeu à "ciência", à política, à economia e à arte. Através dessa síntese, enxergamos a possibilidade de pensar sobre a comunicação do conhecimento desenvolvido no século XVIII e sobre que recursos foram utilizados para essa divulgação. Esse "tema" também se entrelaça com um "tema” de NdC sugerido por Martins (2015): "Comunicação do conhecimento científico dentro da comunidade científica e em domínio público”.

O período setecentista revela, ainda, uma mentalidade orientada para o empirismo científico, acreditando na possibilidade de dominar a natureza e colocá-la a serviço da humanidade e sua racionalidade. Com uma característica essencialmente descritiva, as ilustrações científicas que foram produzidas nesse século buscavam retratar todos os detalhes do espécime de forma naturalística, devendo ser riscados todos os detalhes com o máximo de precisão possível. Para tanto, exigia-se a produção do desenho in loco. Nessa direção, torna-se possível problematizar mais um aspecto relevante de $\mathrm{NdC}$, que 
se refere à observação em um processo de construção de conhecimentos. Mais um "tema" que tem aproximação com a proposta de Martins (2015), quando sugere a "Observação e inferência" como "tema" para discutir sobre métodos, procedimentos e processos da ciência.

Por outro lado, apresentamos em nosso estudo que as ilustrações científicas foram produzidas através de várias técnicas e não apenas a partir da observação direta do fenômeno no espaço natural. Além disso, o naturalista/artista iluminista buscava garantir a fidelidade das suas ilustrações, mas segundo seu próprio julgamento, o que significa, portanto, a presença de elementos criativos e imaginativos na ilustração científica. Enfim, podemos questionar o papel da imaginação e da criatividade na construção do conhecimento científico. De modo semelhante, Martins (2015) sugere como um "tema" para debater o "Problema da origem do conhecimento (científico)" o "Papel da observação, experimentação, lógica, argumentos racionais e pensamento teórico".

Os parágrafos precedentes tiveram o intuito de exemplificar parte de um diálogo entre um estudo historiográfico sobre ilustrações científicas e o ensino de ciências, bem como trazer subsídios para professores/pesquisadores do campo de ensino de ciências interessados em utilizar as ilustrações científicas. Enxergamos as ilustrações científicas históricas como uma alternativa para dialogar sobre ciências, problematizar o seu desenvolvimento, e, especialmente, para mostrar que esse tipo de imagem tem suas potencialidades e que, quando levadas à sala de aula, não merecem ser tratadas, apenas, como recursos figurativos ou motivacionais.

Reconhecemos o desafio de aprender e ensinar sobre ciências por meio de ilustrações científicas, mas também entendemos que se trata de um caminho possível para exercitar a criticidade e a criatividade. Essas ilustrações científicas, na interface com a HFSC e a NdC, abrem espaço para dialogar com a história, com a "ciência", com a arte, com a cultura do século XVIII, e nos permitem (re)construir ideias e (re)pensar a oferta de um ensino de ciências da natureza numa perspectiva mais ampla, diversa e reflexiva.

\section{Conclusões e implicações}

Apresentamos um estudo historiográfico acerca das ilustrações científicas do século XVIII relacionadas com o processo de classificação do mundo natural, especialmente de plantas e animais, com foco em evidenciar a importância e o significado da utilização dessas ilustrações para a sua época. Buscamos, também, compreender o processo de produção das ilustrações científicas no iluminismo, bem como interpretar os elementos característicos retratados nas ilustrações científicas e as suas respectivas funções para os estudos da natureza do período em destaque. Enfim, foi um trabalho focado, especialmente, nas práticas científicas e na cultura visual do século XVIII. 
Além disso, enxergamos que a realização de uma pesquisa histórica sobre ilustrações científicas, bem como a proposição do seu uso em sala de aula, na interface com a HFSC e NdC, compreendem formas de "corrigir" certas concepções de que elas não viabilizariam nenhum tipo de debate ou reflexões por serem dotadas de uma estrutura que possibilitaria uma imediata identificação do objeto retratado. Contudo, como tentamos mostrar ao longo desse trabalho, a ilustração científica é um tipo de recurso que vai além de ser algo intuitivo e atrativo, isto é, compreende um instrumento que carrega um conjunto de ideias e contextos da sua época de produção e que, portanto, precisa ser mais valorizada enquanto meio para aprender e ensinar sobre as ciências e suas práticas.

Em suma, trabalhar com ilustrações científicas do período iluminista é uma alternativa frutífera para (re)construir conhecimentos históricos, científicos, culturais, sociológicos, artísticos, políticos e econômicos e mostrar, ainda, o significado, a necessidade e a relevância da diversidade de ideias, de pessoas, de métodos, de instrumentos e de esforços para se fazer ciência, bem como trazer à luz aspectos relevantes da natureza do trabalho científico e de seu desenvolvimento histórico. E, no âmbito escolar, são elementos que podem ser trabalhados em diferentes componentes curriculares ou tratados de forma interdisciplinar.

Entendemos que esse nosso estudo abre caminhos para releituras acerca das ilustrações científicas do século XVIII. Inclusive, há uma rica literatura ilustrada desse período que precisa ser mais apreciada e analisada em profundidade. Além disso, direcionar o nosso olhar para as ilustrações científicas que foram confeccionadas durante as viagens de exploração no século XVIII, principalmente aquelas expedições que ocorreram em solo brasileiro - as "Viagens Filosóficas" —, compreende uma proposta bastante interessante.

As ilustrações científicas que foram produzidas e utilizadas nesse período das "Viagens Filosóficas" correspondem a instrumentos oportunos para problematizar a relação entre o Brasil e a Europa, e, mais especificamente, entre Brasil e Portugal, além de evidenciar a participação brasileira na produção científica na época iluminista. Esse recorte possibilita, também, que a temática seja explorada por professores de outras áreas de conhecimento, e não apenas por professores de ciências da natureza.

Dito isso, outros "temas" de NdC podem ser identificados, bem como "questões" podem ser propostas, a partir desse contexto histórico e sociocultural de produção das ilustrações científicas envolvendo o Brasil Colônia, como forma de trazer novos debates e reflexões sobre um enfoque que ainda é pouco abordado (ou sequer é citado) nos livros didáticos de ciências, quando falam da ciência do século XVIII.

\section{Referências}

Abrantes, P. (2002). Problemas metodológicos em historiografia da ciência. In W. J. da Silva Filho (Org.), Epistemologia e Ensino de Ciências (pp. 51-91). Arcádia. 
Antunes, A. P., Moreira, I. de C. \& Massarani, L. M. (2015). O descanso dos naturalistas: uma análise de cenas na iconografia oitocentista. História, Ciências, Saúde - Manguinhos, 22(3), 1051-1066. https://doi.org/10.1590/S0104-59702015000300024

Aumont, J. (2012). A imagem. Campinas: Papirus Editora.

Bejarano, N. R. R., Aduriz-Bravo, A. \& Bonfim, C. S. (2019). Natureza da Ciência (NOS): Para além do consenso. Ciência \& Educação, 25(4), 967-982. https://doi. org/10.1590/1516-731320190040008

Bleichmar, D. (2012). Visible Empire: botanical expeditions and visual in the hispanic enlightenment. The University of Chicago Press.

Braga, M., Guerra, A. \& Reis, J. C. (2011). Breve história da ciência moderna, volume 3: Das luzes ao sonho do doutor Frankenstein (séc. XVIII) (2a ed.). Editora Zahar.

Burke, P. (2017). Testemunha ocular: O uso de imagens como evidência histórica. Editora UNESP.

Burke, P. (2008). O que é história cultural? (2a ed.). Editora Zahar.

Costa, P. F. da (2006). A visualização da natureza e o entendimento do mundo vivo. Filosofia e História da Biologia, 1, 247-269. http://www.abfhib.org/FHB/FHB-01/ FHB-v01-15.html

Daston, L. \& Galison, P. (2010). Objectivity. Zone Books.

Eco, U. (2015). História da beleza (5ª ed.). Editora Record.

Faria, M. F. de. (2001). A imagem útil: José Joaquim Freire (1760-1847) desenhador topográfico e de história natural - arte, ciência e razão de estado no final do antigo regime. Universidade Autônoma Editora.

Findlen, P. (2000). Courting nature. In N. Jardine, A. J. Secord \& E. C. Spary, Cultures of Natural History (pp. 57-74). Cambridge University Press.

Ford, B. J. (1993). Images of science: a history of scientific illustration. Oxford University Press.

Foss, L. (1971). Art as Cognitive: Beyond scientific realism. Philosophy of Science, 38(2), 234-250. http://www.jstor.org/stable/186782

Gandolfi, H. E. (2019). In defence of non-epistemic aspects of nature of science: Insights from an intercultural approach to history of science. Cultural Studies of Science Education, 14, 557-567. https://doi.org/10.1007/s11422-018-9879-8

Gil Pérez, D., Montoro, I. F., Alís, J. C., Cachapuz, A. \& Praia, J. (2001). Para uma imagem não deformada do trabalho científico. Ciência \& Educação, 7(2), 125-153. https://doi. org/10.1590/S1516-73132001000200001

Gombrich, E. H. (2015). A história da arte. LTC. 
Gombrich, E. H. (2012). Os usos das imagens: Estudos sobre a função social da arte e da comunicação visual. Bookman.

Hankins, T. L. (2010). Science and the Enlightenment. Cambridge University Press.

Jardim, W. T. \& Guerra, A. (2017). República das Letras, Academias e Sociedades Científicas no século XVIII: A garrafa de Leiden e a ciência no ensino. Caderno Brasileiro de Ensino de Física, 34(3), 774-797. https://doi.org/10.5007/2175-7941.2017v34n3p774

Koener, L. (2000). Carl Linnaeus in his time and place. In N. Jardine, A. J. Secord \& E. C. Spary, Cultures of Natural History (pp. 145-162). Cambridge University Press.

Kury, L. (2015). O naturalista Veloso. Revista de História, (172), 243-277. https://doi. org/10.11606/issn.2316-9141.rh.2015.98752

Kusukawa, S. (2011). The role of images in the development of Renaissance natural history. Archives of Natural History, 38(2), 189-213. https://doi.org/10.3366/anh.2011.0028

Kusukawa, S. (2000). Illustrating nature. In M. Frasca-Spada \& N. Jardine, Books and the sciences in history (pp. 90-113). Cambridge University Press.

Lee, J. (1788). An introduction to botany: Containing an explanation of the theory of that science, extracted from the works of Dr. Linnaeus with twelve copper-plates, two explanatory tables, an appendix and glossary. London: J.F. and C. Rivington, L. Davis, B. White and Son, S. Crowder, C. Dilly, G. G. J. and J. Robinson, T. Cadell and R. Baldwin. Lindroth, S. (2007). Carl Linnaeus. In C. C. Gillispie (Org.), Dicionário de biografias científicas (pp. 1706-1713). Contraponto.

Linnaei, C. (1737). Flora Lapponica exhibens plantas per Lapponiam crescentes, secundum Systema Sexuale collectas in itinere impensis. Gale.

Linnaei, C. (1749). Pan Svecicu. Upsaliae.

Linnaei, C. (1751). Philosophia botânica: in qua explicantur fundamenta botanica cum definitionibus partium, exemplis terminorum, observationibus rariorum, adiectis figuris aeneis. Viennae.

Marques, A. J. (2012). O iluminismo no mundo luso-brasileiro. Editora Sapere.

Martins, A. F. P. (2015). Natureza da ciência no ensino de ciências: uma proposta baseada em “temas" e "questões". Caderno Brasileiro de Ensino de Física, 32(3), 703-737. https:// doi.org/10.5007/2175-7941.2015v32n3p703

Matthews, M. R. (1998). In defense of modest goals when teaching about the Nature of Science. Journal of Research in Science Teaching, 35(2), 161-174. https://doi.org/10.1002/ (SICI)1098-2736(199802)35:2\%3C161::AID-TEA6\%3E3.0.CO;2-Q

Moura, B. A. (2014). O que é natureza da ciência e qual sua relação com a História e Filosofia da ciência? Revista Brasileira de História da ciência, 7(1), 32-46. https://www. sbhc.org.br/arquivo/download?ID_ARQUIVO=1932 
Moura, C. B. de \& Guerra, A. (2016). História Cultural da Ciência: Um Caminho Possível para a Discussão sobre as Práticas Científicas no Ensino de Ciências? Revista Brasileira de Pesquisa em Educação em Ciências, 16(3), 725-748. https://periodicos.ufmg.br/index. $\mathrm{php} / \mathrm{rbpec} / \mathrm{article} / \mathrm{view} / 4497$

Nickelsen, K. (2006). Botanists, Draughtsmen and Nature: the construction of eighteenthcentury botanical illustration. Studies in History and Philosophy of Science, 1(37), 1-25. https://doi.org/10.1016/j.shpsc.2005.12.001

Ogilvie, B. W. (2006). The science of describing: Natural history in Renaissance Europe. The University Of Chicago Press.

Pataca, E. M. (2005). A Ilha do Marajó na Viagem Philosophica (1783-1792) de Alexandre Rodrigues Ferreira. Boletim do Museu Paraense Emílio Goeldi. Ciências Humanas, 1(1), 149-169.

Pimentel, J. (2010). ¿Qué es la historia cultural de la ciencia? Arbor, 186(743), 417-424. https://doi.org/10.3989/arbor.2010.743n1206

Prestes, M. E. B. (1997). A investigação da natureza no brasil-colônia (Dissertação de Mestrado, Universidade de São Paulo, São Paulo).

Prestes, M. E. B., Oliveira, P. \& Jensen, G. M. (2009). As origens da classificação de plantas de Carl von Linné no ensino de biologia. Filosofia e História da Biologia, 4, 101137. http://www.abfhib.org/FHB/FHB-04/FHB-v04-04.html

Santaella, L. (2012). Leitura de imagens. Editora Melhoramentos.

Santos, F. S. dos. (2006). A botânica no ensino médio: será que é preciso apenas memorizar nomes de plantas? In C. C. Silva (Org.), Estudos de história e filosofia das ciências: subsídios para aplicação no ensino (pp. 223-243). Livraria da Física.

Scoditti, F. de M. (2011). Memória e invenção em história natural: Intervenção artística em contexto museológico (Dissertação de Mestrado, Faculdade de Belas-Artes da Universidade do Porto, Porto, Portugal).

Silva, M. A. M. da (2016). A utilização da controvérsia mendeliano-biometricista na questão da hereditariedade no início do século XX: um caminho para se trabalhar a hereditariedade na educação básica? (Dissertação de Mestrado, Centro Federal de Educação Tecnológica Celso Suckow da Fonseca, Rio de Janeiro).

Smith, P. H. (2006). Art, Science, and Visual Culture in Early Modern Europe. Isis, 97(1), 83-100. https://doi.org/10.1086/501102

Stearn, W. T. (June, 1966). The use of bibliography in natural history. In T. R. Buckman (Org.), Bibliography and Natural History (pp. 1-26). Kansas, Lawrence. University of Kansas Libraries.

Swan, C. (2011). Illustrated Natural History. In S. Dackerman (Org.), Prints and the Pursuit of Knowledge in Early Modern Europe (pp. 186-199). Harvard University Press. 
Vitor, F. C. \& Martins, A. F. P. (2020). Ilustrações científicas no ensino de ciências: um panorama a partir de periódicos brasileiros. Alexandria: Revista de Educação em Ciência e Tecnologia, 13(2), 99-121. https://doi.org/10.5007/1982-5153.2020v13n2p99

\section{Fernanda Cavalcanti Vitor}

Universidade Federal do Rio Grande do Norte Natal, Rio Grande do Norte, Brasil dinhacavalcanti@yahoo.com.br

André Ferrer Pinto Martins

Universidade Federal do Rio Grande do Norte Natal, Rio Grande do Norte, Brasil aferrer34@yahoo.com.br

Manifestação de Atenção às Boas Práticas Científicas e de Isenção de Interesse

Os autores declaram ter cuidado de aspectos éticos ao longo do desenvolvimento da pesquisa e não ter qualquer interesse concorrente ou relações pessoais que possam ter influenciado o trabalho relatado no texto. 